\title{
Safety and efficacy of pericardial endoscopy by percutaneous subxyphoid approach in swine heart in vivo
}

\author{
Takehiro Kimura, MD, ${ }^{\text {a }}$ Shunichiro Miyoshi, MD, PhD, ${ }^{\text {a }}$ Seiji Takatsuki, MD, PhD, ${ }^{\text {a }}$ Kojiro Tanimoto, MD, \\ $\mathrm{PhD},{ }^{\mathrm{a}}$ Kotaro Fukumoto, MD, PhD, ${ }^{\mathrm{a}}$ Kyoko Soejima, $\mathrm{MD}, \mathrm{PhD},{ }^{\mathrm{b}}$ and Keiichi Fukuda, MD, PhD ${ }^{\mathrm{a}}$
}

\begin{abstract}
Objective: A nonsurgical approach from the epicardial surface is useful for various cardiac interventions, such as positioning of the left ventricular lead for cardiac resynchronization therapy and epicardial ablation. Stem cell delivery on the epicardial surface can be considered in the future if good quality of visualization can be obtained. However, because the pericardial space is limited, hemodynamic conditions may deteriorate with pericardial endoscopy. Therefore, the feasibility and efficacy of pericardial endoscopy were examined by using readymade endoscopes.
\end{abstract}

\begin{abstract}
Methods: Anesthetized swines $(26-61 \mathrm{~kg} ; \mathrm{n}=6)$ were used for the experiment. Electrocardiogram, femoral artery blood pressure, and oxygen saturation by pulse oximetry were continuously monitored during the procedures. Guided by the fluoroscopy, sheaths were advanced to the pericardial space using the modified Seldinger technique from the subxyphoid space.
\end{abstract}

Results: After insertion of an endoscope with a maximum diameter of $6.9 \mathrm{~mm}$, hemodynamic parameters were stable during the procedure with atropine. Stable and acceptable endoscopic images were obtained. Minor operations can be performed with pericardial endoscopic-guided laparoscopic forceps with no complications.

Conclusions: The endoscopic pericardial procedure is effective and feasible. This procedure can increase the possibility and efficacy of nonsurgical treatment for cardiac diseases. (J Thorac Cardiovasc Surg 2011;142:181-90)

Video clip is available online.

Recent progress in minimally invasive therapy has dramatically changed the treatment of heart disease. Percutaneous transluminal approaches (eg, coronary angioplasty ${ }^{1}$; catheter ablation $^{2,3}$; pacemaker, implantable cardioverter defibrillator, and cardiac resynchronization therapy ${ }^{4}$; and percutaneous heart valve replacement ${ }^{5}$ ) have provided significant therapeutic benefit to patients with a minimal burden. However, it is still difficult to reach the epicardial targets by the transluminal approach. Minimally invasive epicardial approaches may aid epicardial biopsy, implantation of left ventricular epicardial pacing lead for cardiac resynchronization therapy, and ablation for epicardial arrhythmic

\footnotetext{
$\overline{\text { From Cardiology, }}{ }^{\text {a }}$ Keio University School of Medicine, Tokyo, Japan; and Cardiology, ${ }^{\text {b }}$ St. Marianna University School of Medicine, Kawasaki, Japan.

Experiments were partially supported by the Japanese Society for Promotion of Science, Grant-in-Aid for Scientific Research, the Ministry of Health, Labor, and Welfare of Japan, and the Suntory Fund for Advanced Cardiac Therapeutics, Keio University School of Medicine. Part of the work was performed at the Keio Research Laboratory Center for Integrated Medical Research.

Disclosures: Authors have nothing to disclose with regard to commercial support.

Received for publication Aug 1, 2010; revisions received Sept 5, 2010; accepted for publication Sept 11, 2010; available ahead of print Nov 12, 2010.

Address for reprints: Takehiro Kimura, MD, 35 Shinanomachi Shinjuku-ku Tokyo, Japan 160-8582, Cardiology, Keio University School of Medicine (E-mail: veritas@bp.iij4u.or.jp).

$0022-5223 / \$ 36.00$

Copyright (c) 2011 by The American Association for Thoracic Surgery doi:10.1016/j.jtcvs.2010.09.050
}

substrate. Furthermore, such approaches are also applicable for transplantation of stem cells into the myocardium. Although significant progress in research for cardiac stem cells has been made, research for optimization of the transplantation procedures is sparse. Compared with catheterbased transluminal stem cell transplantation, ${ }^{6}$ epicardial transplantation poses less risk for infusion of stem cells into the bloodstream and systemic dissemination and microembolization of overflowed stem cells. ${ }^{7,8}$ Pericardial endoscopy is also applicable to direct genetic transfection of the gene to the local myocardium, so-called gene therapy. ${ }^{9}$

Pericardiocentesis using the Seldinger maneuver from the subxyphoid to the pericardial space without obvious pericardial effusions is safe ${ }^{10}$ and allows the epicardial target to be reached with minimal invasion. ${ }^{11,12}$ However, it is difficult to perform the operation within the pericardial space because of numerous obstacles: the coronary vessels, adipose tissue, lung, and phrenic nerves. Therefore, endoscopic guidance is required for the operation. Epicardial biopsy, ${ }^{13,14}$ epicardial ablation, ${ }^{15}$ pulmonary vein isolation, ${ }^{16}$ and implantable cardioverter defibrillator lead placement ${ }^{17}$ using pericardial endoscopy have been reported, but risk of injury to arteries, organs, and nerves still remains. The relation among the diameter of the endoscope, material of the sheath, and hemodynamic parameters has not been extensively described. Epicardial inflammation as a chronic effect should be further evaluated. Techniques to obtain a more refined view for critical procedures are not well developed.

Therefore, we evaluated the safety of this procedure, not only for short time periods to assess hemodynamic changes 


\section{Abbreviation and Acronym \\ $\mathrm{CCD}=$ charge-coupled device}

but also for longer periods to assess chronic complications, including infections, chronic pericarditis, and other lifethreatening complications. Among various ready-made endoscopes, adequate types for pericardial endoscopy were selected. To identify the anatomy of the heart, we defined the basic method to steer the endoscope and stabilize the view.

\section{MATERIALS AND METHODS \\ Surgical Procedure}

All experimental protocols were approved by the institutional ethical committee. Studies were performed in 6 mongrel swine weighing 26 to $61 \mathrm{~kg}$. After nitrous oxide inhalation, swine were intubated and ventilated with room air by the constant-volume cycled respirator (Harvard Apparatus model 607; Harvard Appatatus, Hoilliston, Mass) and anesthetized with $1.5 \%$ to $2 \%$ isoflurane. A fluid-filled cannula was placed in the left carotid artery and connected to the transducer to monitor arterial blood pressure. A great cervical vein cannula was used to infuse normal saline at a rate of 100 to $200 \mathrm{~mL} / \mathrm{h}$ to replace spontaneous fluid losses and to inject drugs. Electrocardiogram and pulse oxymetry were continuously monitored.

Mechanical irritation of the pericardium may cause Bezold-Jarisch (vagal) reflex and bradycardia that can result in significant deterioration of hemodynamics; therefore, immediately before the pericardiocentesis, $1 \mathrm{mg}$ of atropine was administered to suppress the vagal reflex and an additional 0.5 $\mathrm{mg}$ of atropine was administered when the heart rate decreased to less than 70 beats/min. After local anesthesia, an $18 \mathrm{G}$ epidural needle connected to a $10-\mathrm{mL}$ syringe filled with contrast material was inserted from the subxyphoid toward the heart shadow under x-ray fluoroscopic guidance. ${ }^{18}$ After puncture of the pericardial membrane, the guide wire (outer diameter $=0.81 \mathrm{~mm}$ ) was inserted into the pericardial space, and the catheter sheath was inserted along the guide wire to the pericardial space. We used 6 types of sheaths. The size, stiffness, shape, and material of each sheath are shown in Figure 1. Sheaths were selected in accordance with the diameter of the endoscope. Six ready-made endoscopes (Olympus Medical Systems Corp, Tokyo, Japan) were used. The model number, visual angle, direction of lens, size, device ports, optical image system, and features of the endoscopes are shown in Figure 2. The endoscopes are advanced through the variety of sheaths, checking the effects of hemodynamic data, controllability, and quality of the view. We tried to maintain a clear view by regulating the amount of air and saline insufflations through the working port of the endoscope. Measured vital signs, fluoroscopic images, and endoscopic images were analyzed and evaluated after each experiment. To assess chronic effects, animals were kept alive for 2 weeks and then inspected for evidence of injuries to pericardium, lungs, and other organs.

\section{RESULTS \\ Effect of Endoscope and Sheath Size on Hemodynamic Parameters}

The performance of the endoscope increases as a function of the diameter of the endoscope; however, the hemodynamics may deteriorate. Thus, the adequate diameter of the endoscope with acceptable visual images without significantly changing the hemodynamics should be determined. Representative hemodynamic data during pericardial endoscopy are shown in Figure 3. The endoscope with the largest diameter (6.9 $\mathrm{mm}$ in ES5) did not cause significant deterioration of hemodynamic parameters; thus, the endoscope with a diameter less than $6.9 \mathrm{~mm}$ is acceptable.

To obtain a clear image, design of the optomechanical device is important. Mounting a charge-coupled device (CCD) camera on the tip of the endoscope to connect directly to the objective lens significantly improved image quality (Figure 4, D, F). However, this is difficult to do with a thinner endoscope because of limitations on the miniaturization of the CCD camera. Therefore, the CCD camera was mounted

\begin{tabular}{|c|c|c|c|c|c|c|c|c|}
\hline No & ID(F) & Model & Material & Stiffness & Shape & $\begin{array}{l}\text { Check } \\
\text { valve }\end{array}$ & Image & \\
\hline $\mathrm{SH} 1$ & 10 & $\begin{array}{l}\text { radifocus } \\
\text { introdu cer-IIH }\end{array}$ & polypropylene & soft & curved & tight & & \\
\hline $\mathrm{SH} 2$ & 15 & hand made & polypropylene & soft & straight & tight & & \\
\hline $\mathrm{SH} 3$ & 21 & handmade & $\begin{array}{l}\text { polytetra- } \\
\text { flu oroethylene }\end{array}$ & floppy & floppy & tight & $\mathrm{Cr}$ & $=$ \\
\hline $\mathrm{SH} 4$ & 18 & $\begin{array}{l}\text { capiox } \\
\text { percutaneous } \\
\text { catheter kit }\end{array}$ & polypropylene & hard & curved & none & & \\
\hline $\mathrm{SH} 5$ & 16.5 & $\begin{array}{l}\text { TOLOCKER } \varnothing \\
5.5 \mathrm{~mm}\end{array}$ & stainless & solid & straight & loose & & \\
\hline $\mathrm{SH} 6$ & 33 & $\begin{array}{l}\text { TOLOCKER } \varnothing \\
11 \mathrm{~mm}\end{array}$ & stainless & solid & straight & loose & & $=$ \\
\hline
\end{tabular}

FIGURE 1. List of the sheaths used. Internal diameter in French, model name, material, stiffness, shape of the tip, durability of the check valve, and an image of the sheath (white scale bars $=5 \mathrm{~cm}$ ). ID, Internal diameter; $F$, French. 


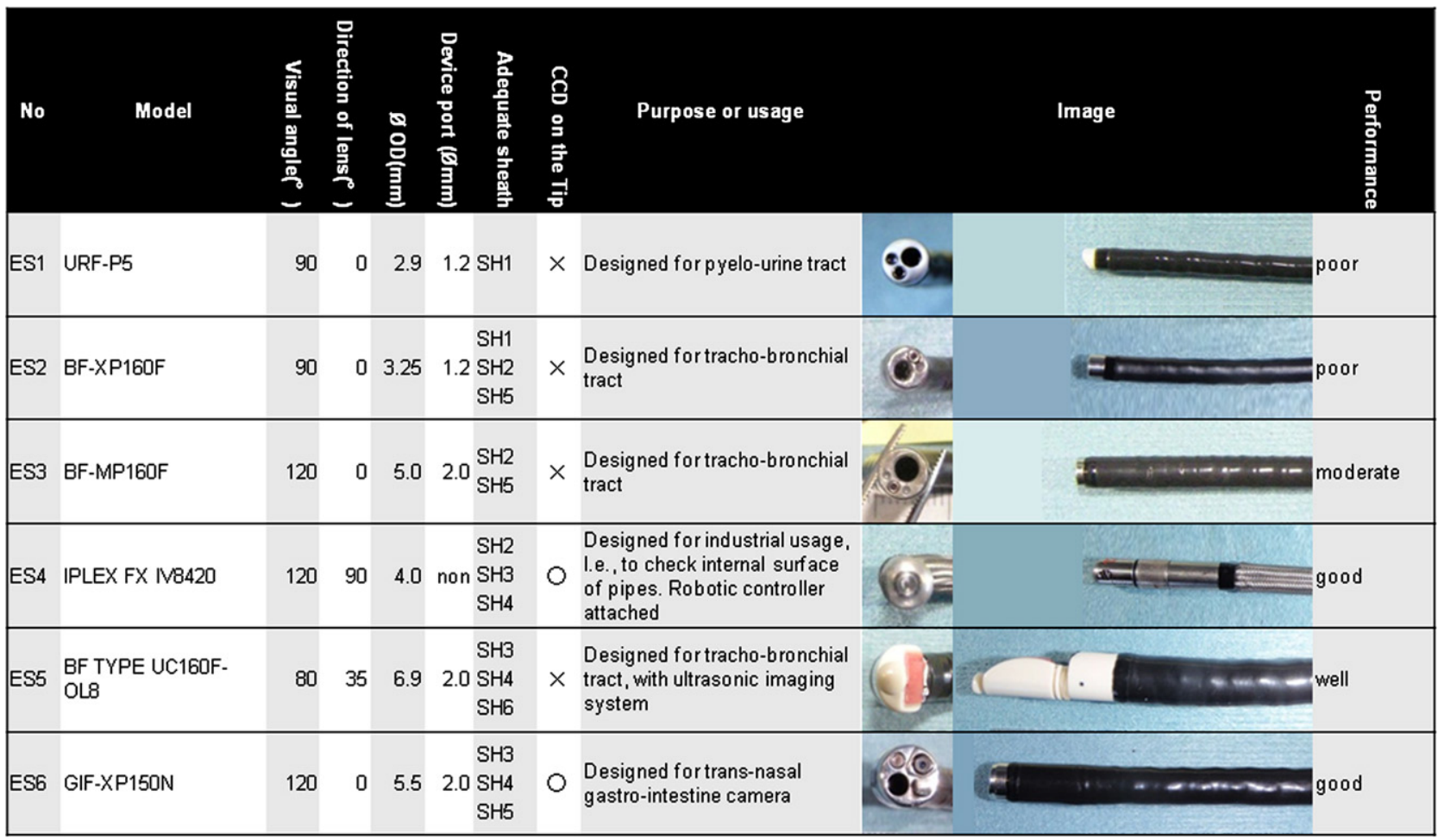

FIGURE 2. List of the endoscopes used. Models of the endoscope, visual angle, direction of lens (angle along the longitudinal axis), outer diameter, inner diameter of utility port, adequate sheath, whether CCD camera is mounted on the tip or not, features of the endoscope, images of the endoscope (scale bars $=5 \mathrm{~mm}$ ), and the performance of the endoscope in the pericardial space. $C C D$, Charge-coupled device; $O D$, outer diameter.

on the body of the thin endoscope and connected to the objective lens by a bundle of flexible optic fibers, which significantly improved image quality (Figure $4, A-C, E$ ). Because the thickest endoscope (outer diameter $=6.9 \mathrm{~mm}$ ) was hemodynamically tolerable, we concluded that mounting the CCD on the endoscope tip was adequate for pericardial endoscopy. Taking these results into account, we selected ES4 and ES6 as adequate for a pericardial endoscope.

The selection of the sheath was more important. To insert a large endoscope into a pericardial space, sheaths with a larger diameter are required, but ready-made larger sheaths are uncommon (SH1, SH5, SH6) and most of them are solid (SH5, SH6). Solid sheaths were unstable in positioning, and use of SH6 sometimes caused significant deterioration of hemodynamic parameters. Therefore, after insertion of the endoscope, withdrawal of the sheath was required to stabilize hemodynamic parameters (Figure 3, A). Accordingly, we prepared our handmade flexible sheath with a larger diameter (SH2, SH3, SH4), which did not cause a significant change in hemodynamic parameters (Figure 3, B). A check valve on the sheath was also important to maintain the volume of air in the pericardial space. The SH3 exhibited the best performance.

\section{Clear Visualization}

Our first achievement was to establish the method to obtain a clear view of the pericardial space by endoscopy. Expansion of the pericardial space by air enables us to maintain a distance from the camera to the heart surface, which is necessary for a clear view. An equal volume of saline was injected in some experiments, but a good image was not obtained and there was significant deterioration of hemodynamic parameters (Figure 3, B). Therefore, we decided to inject air to expand the pericardial space.

A larger amount of air infusion provides better vision, but on the other hand it may deteriorate hemodynamic parameters by inhibiting diastolic function of the ventricles. Injection of 100 to $200 \mathrm{~mL}$ of gas into the pericardial space caused no hemodynamic changes $( \pm 5 \mathrm{~mm} \mathrm{Hg}$ ) and allowed a stable view. In addition, resulting decreases in systolic blood pressure were less than $10 \mathrm{~mm} \mathrm{Hg}$, which is almost tolerable.

\section{Orientation of the View}

Determination of orientation of the view is important for an endoscopic-guided operation. Because of strong motion artifacts in the visual field, $\mathrm{x}$-ray fluoroscopic guidance is essential to determine orientation of the tip of the endoscope. Furthermore, recognition of several landmarks of the heart can also help in understanding orientation. Infusion of 10 to $20 \mathrm{~mL}$ of saline and 50 to $100 \mathrm{~mL}$ of air into the pericardial space gives us a clear view of fluid levels. The fluid level is an important compass for horizontal direction of the visual field. Landmarks (Figure 5) in the visual 


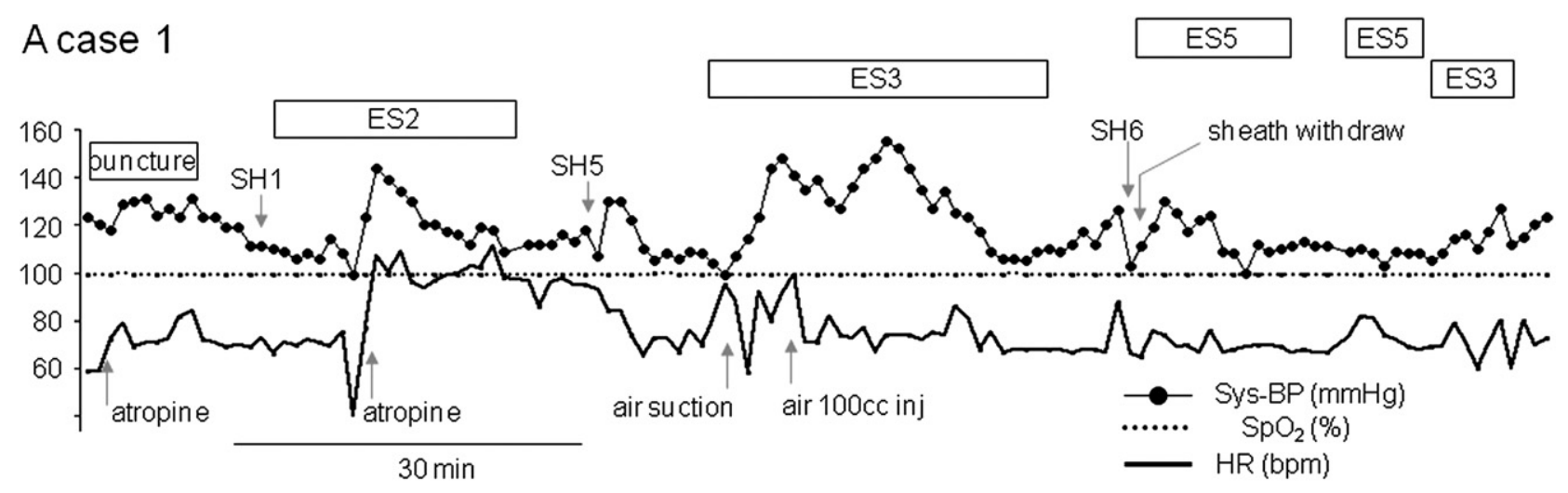

\section{B case 2}

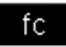

fc

fc



FIGURE 3. Systolic blood pressure, pulse oxymetry, and heart rate as a function of time during procedures of representative cases. Upper white bars in the graphs denote period of endoscope insertion, and black bars denote insertion of laparoscopic forceps. Upper gray arrows denote the time of insertion of each sheath, and lower gray arrows denote the timing of administration of atropine, suction, and injection of air/saline into the pericardial space. Hemodynamic parameters during procedure are well within tolerable limits. $S y s-B P$, Systolic blood pressure; $S_{p} O_{2}$, pulse oxymetry; $H R$, heart rate; $E S$, endoscope; $f c$, forceps; $S H$, sheath.

field also help us to recognize the position of the tip of the endoscope. Left and right atrial appendages are clear landmarks (Figure 5, $A, C, M, P, Q, S, T, U$ ). Other heart landmarks, that is, the aortic root (Figure $5, K$ ), pulmonary veins (Figure $5, G, N$ ), superior vena cava (Figure $5, E$ ), and coronary arteries (Figure 4, A-F; Figure 5, R), also give us a clue to define the orientation. Adjacent organsthe lung, diaphragmatic membrane (Figure 5, $I, W$ ), and puncture site (Figure 5, $V$ - can be good landmarks.

\section{Control of Endoscopes}

It is an advantage to understand the movement of the endoscope to stabilize the tip of the device at the exact location. After the modified Seldinger technique, the anteroapical portion of the pericardium was penetrated by sheaths. By advancing and retracting the endoscope, the tip of the endoscope simply moved forward and backward along the anterior interventricular groove. In this manner, the endoscope was straight, the x-ray showed an "I-shape" configuration, and the heart was observed as in an upward-viewing manner (apex to base direction, Figure $6, F$ ). As the endoscope was advanced, the left anterior descending coronary artery (Figure $4, A, E, F$ ), left atrial appendage (Figure 4, E; Figure 5, $A, M, S, T$ ), and aortic root were observed (Figure 5, $K$ ). By bending the endoscopic tip toward the right side, the outflow tract and right ventricle (Figure 5, $O$ ) were observed; by bending toward the left, the left pulmonary veins could be observed (Figure 5, G). However, this view was unstable; because the support (backup) of the shaft was only a shallow interventricular groove, the tip was easily dislodged. Therefore, another endoscopic control is required to observe the whole heart.

When we gently advanced the endoscope in the I-shape configuration under a fluoroscopic guide (Figure 6, $A, F$ ), the tip was trapped at the position along the roof (cranial end, Figure $6, B$ ) of the pericardial space, between the right ventricular outflow tract and the left atrial appendage. At this position, if we rotated the shaft clockwise and advanced the endoscope with maximally bending the tip 


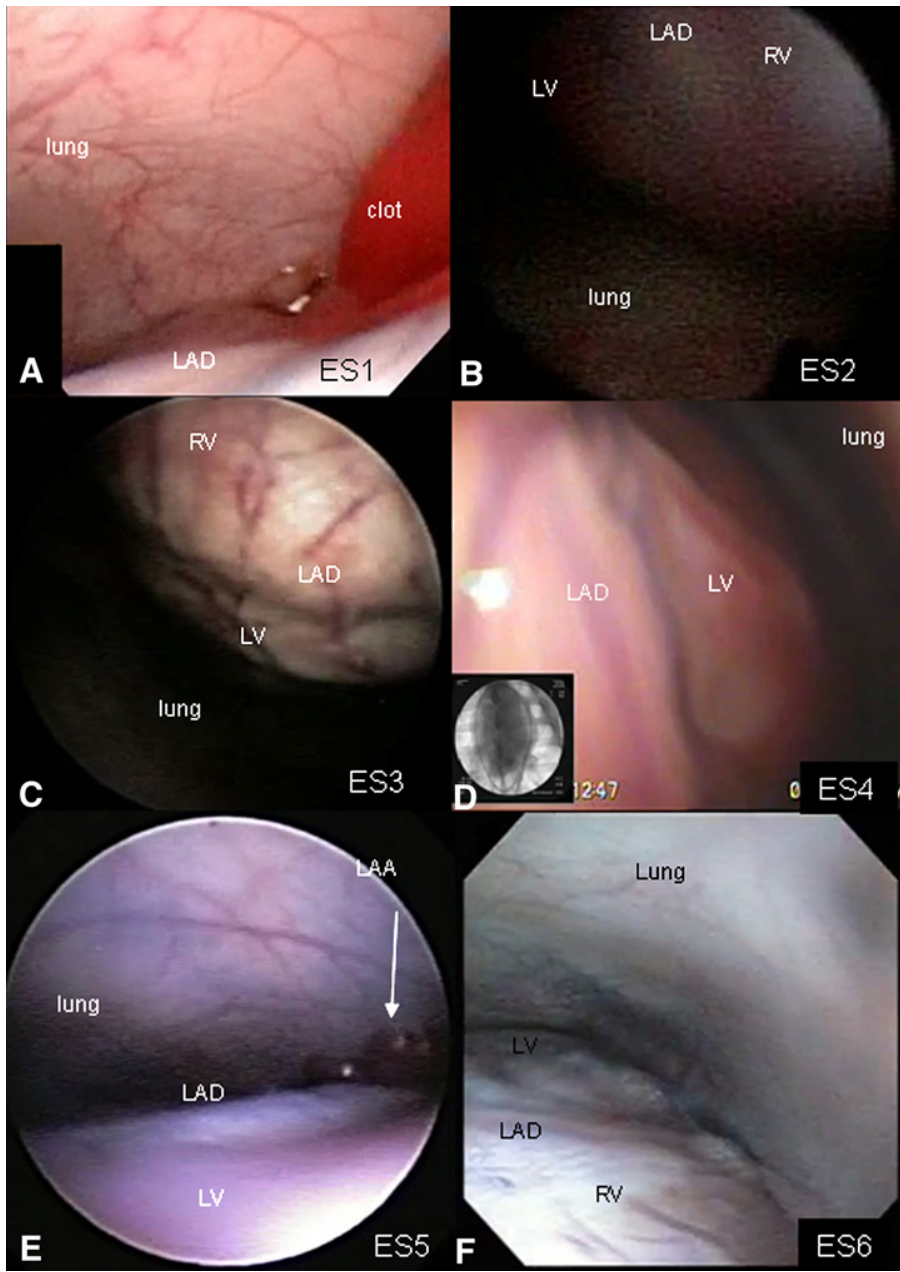

G

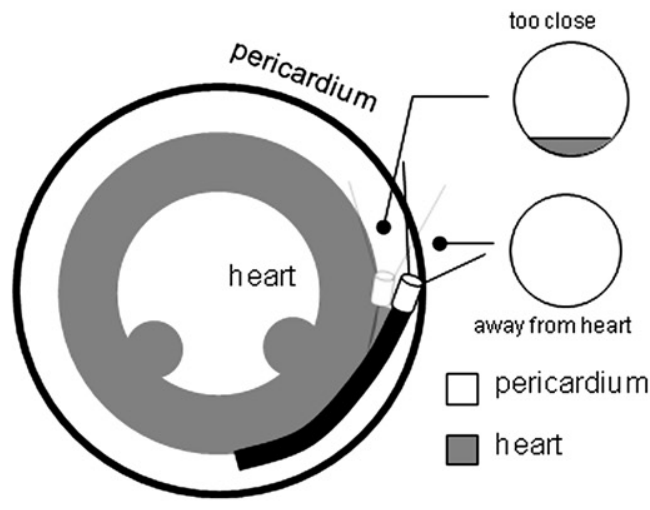

H

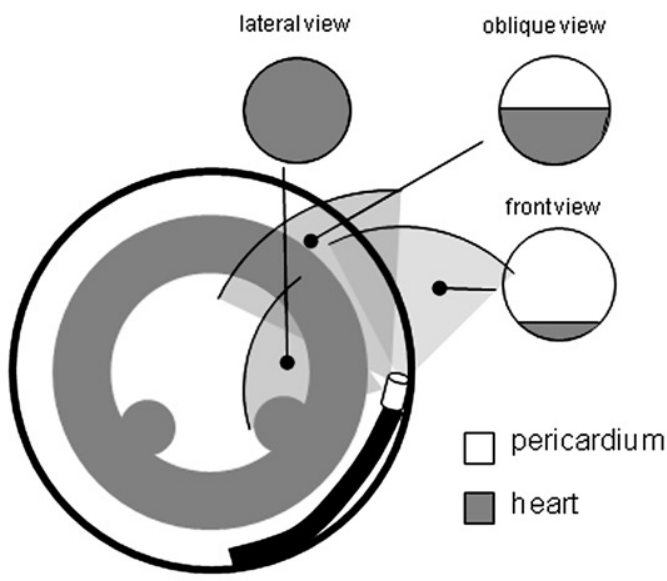

FIGURE 4. A-F, Representative images of left anterior descending artery observed by each endoscope (denoted right bottom, number corresponding to it in Figure 1). It is difficult to front-view the endoscope with a narrow visual angle (A, B). Images of the endoscope without mounting the CCD on the tip (C, E) are fuzzy. Images of the endoscope with the CCD on the tip (D, F) are vivid. G, H, Schematic diagram of spatial configuration of endoscope in the pericardial space and its visual field. G, If the head of the front-view endoscope is directed to the heart surface, the objective lens gets too close to the heart surface. On the other hand, if the endoscope is tipped away from the heart surface, the visual field of the endoscope also tips away from the heart. H, The relation between the visual field and the direction of the objective lens. $L A D$, Left anterior descending artery; $L V$, left ventricle; $E S$, endoscope; $R V$, right ventricle.

(Figure $6, C$ ), the tip of the endoscope could be advanced into the right side of the pericardial space. The middle shaft was turned around at the caudal roof of the pericardium, resulting in a so-called inverted $\mathrm{U}$-shape right-side configuration (Figure $6, D, E, G, H$ ), allowing the heart to be observed as in a downward-viewing manner (base to apex direction). On the other hand, if we rotated the shaft counterclockwise and advanced the endoscope, the tip of the endoscope could go through the left side of the heart, and a so-called inverted U-shape left-side configuration could be achieved. By use of the inverted U-shape configurations, we could observe every portion of the epicardium (Figure 6, $H$; Video 1).

To effectively control pericardial endoscopy, it is important to take into account the position of backup of the shaft and fulcrum at the point of bending. First, the shaft was fixed at the puncture point of the pericardium. In the I-shape configuration, the shaft was moderately backed up by the anterior interventricular groove, the rotation of the shaft did not help steering devices, and the fulcrum point of bending was only the epicardium. Therefore, it was difficult to keep a distance between the objective lens and the epicardial surface (Figure 4, $G$ ), resulting in loss of focus and significant halation (Figure 5, X). However, when the tip was advanced and bent, the visual field was directed toward the pericardium and kept a distance from the epicardial surface (Figure 4, $G$ ). Finally, in the inverted U-shape configuration, the middle of the shaft was strongly backed up by the whole pericardium and we could steer the devices by rotating the shaft. This configuration enabled us to keep an appropriate distance from the epicardial surface (Figure 4, H; Video 2). 


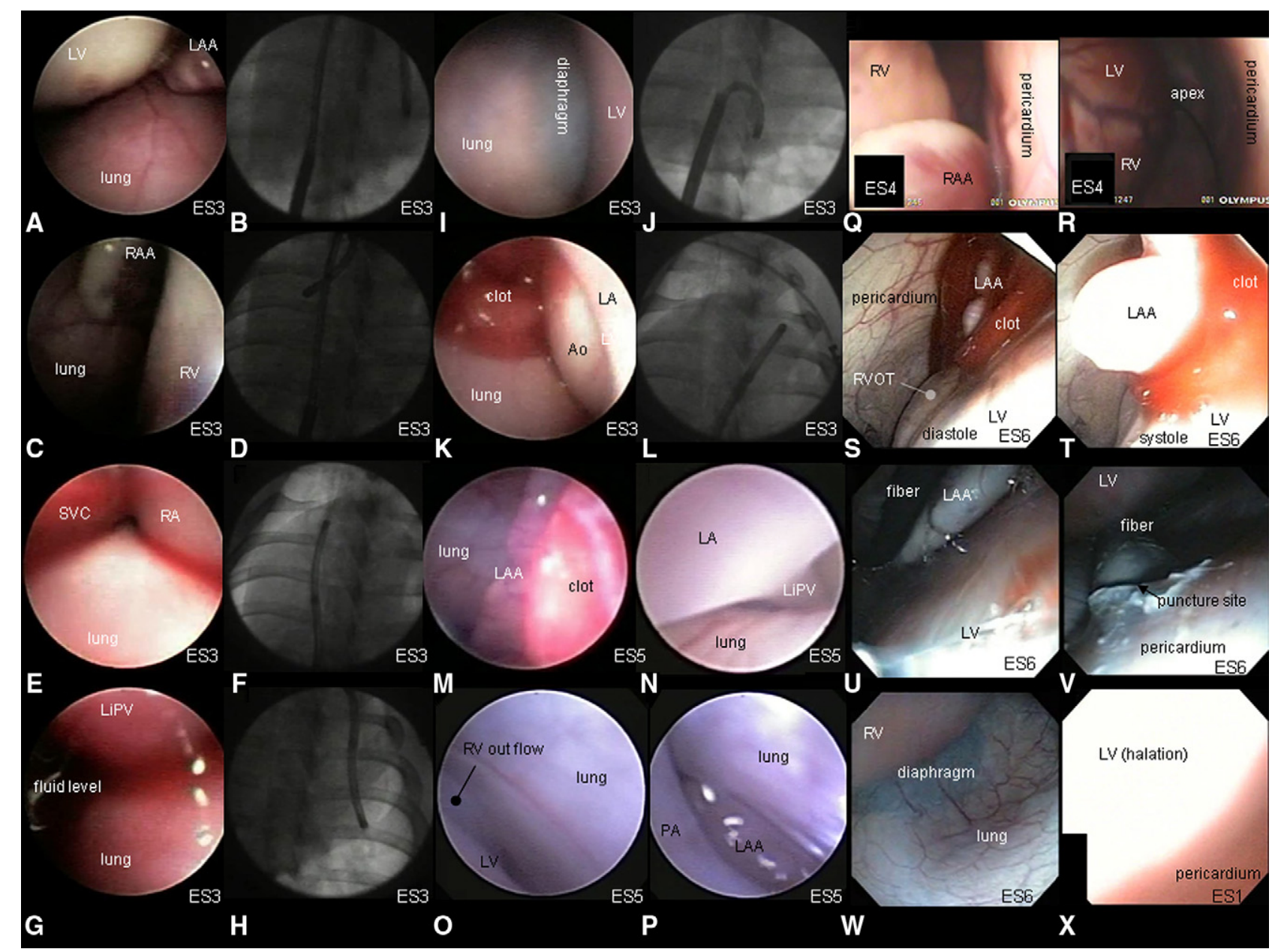

FIGURE 5. Representative images obtained by endoscopy and fluoroscopy. Endoscopic images (A, C, E, G, I, K) obtained by ES3 and corresponding fluoroscopic images (B, D, F, H, J, L, respectively). A, Left atrial appendage and lateral wall of left ventricle. C, Right atrial appendage and lateral wall of right ventricle. E, Superior vena cava and right atrium. G, Left inferior pulmonary vein. I, Pericardium at the diaphragm looks pale compared with pericardium at the lungs. K, Left ventricular outflow tracts. Aortic root and left atrium can be observed. M-P, Endoscopic images obtained by ES5. Left atrial appendage $(\mathrm{M}, \mathrm{P})$, left inferior pulmonary vein $(\mathrm{N})$, and pulmonary artery outflow tract $(\mathrm{O}, \mathrm{P}) . \mathrm{Q}, \mathrm{R}$, Endoscopic images obtained by ES4. Right atrial appendage $(\mathrm{Q})$, right ventricle $(\mathrm{Q}, \mathrm{R})$, and ventricular apex (apex, R). S-W, Endoscopic images obtained by ES6. S, T, Sequential image showing dynamic motion of left atrial appendage. U, Left atrial appendage and body of fiber itself. V, Pericardial puncture site and the body of fiber itself. W, Pericardium at the diaphragm. The quality of the images obtained by ES6 is superior to that obtained by ES3. X, Image obtained by ES1. By using the front-view ES with a narrow visual angle, it is difficult to observe the heart surface without significant halation. Ao, Aortic; $E S$, endoscopy; $L A$, left atrium; $L A A$, left atrial appendage; $L i P V$, left inferior pulmonary vein; $L V$, left ventricle; $P A$, pulmonary artery; $R A$, right atrium; $R A A$, right atrial appendage; $R V$, right ventricle; $S$, diastole; $S V C$, superior vena cava; $T$, systole.

\section{Feasibility of Minor Surgery}

We tested the feasibility of endoscope-guided small operations in the pericardial space. To simulate transplantation of stem cells into the myocardium from the epicardium, we injected Indian ink into the epicardium via endoscope. A 1-mL syringe with $0.2 \mathrm{~mL}$ of Indian ink was connected to a 22G needle for endoscopy (NA-201SX-4022; Olympus, Tokyo, Japan). The needle tip was insulated by external Teflon tubing to avoid injury to the coronary vessels. The needle was attached to the surface of the left ventricular free wall via a utility port (Figure $7, A$ ). After positioning of the tip, the internal needle was protruded into the myocardium, and then Indian ink was injected without severe hemorrhage (Figure 7, B). By protruding the external tube, the objective lens and surface of the heart were stabilized to significantly reduce strong motion artifacts, and adequate working distance was achieved (Figure 7, C).

Rigid laparoscopic forceps are essential for endoscopeguided surgery; however, such rigid forceps may compress the heart and deteriorate hemodynamic parameters. Therefore, a flexible endoscope (ES6) and rigid laparoscopic forceps (Figure 7,E) were inserted simultaneously to perform 


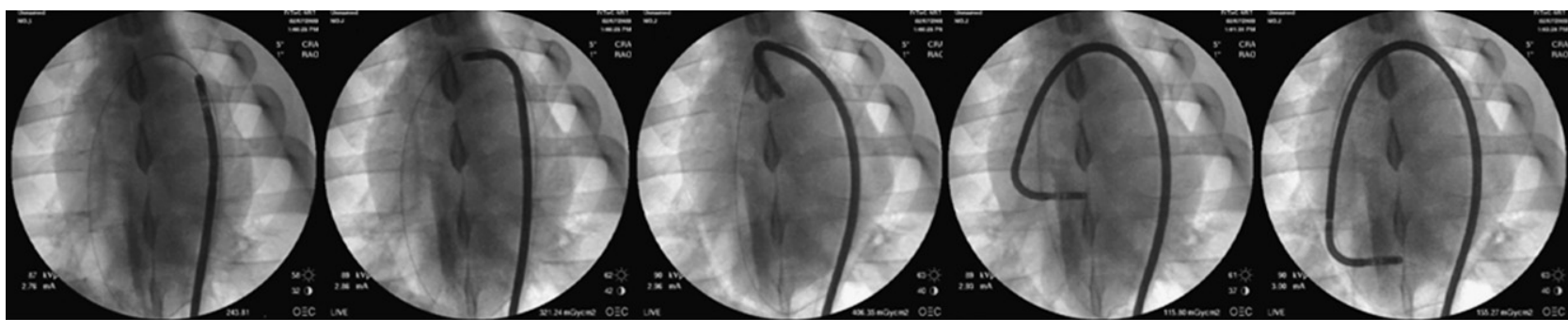

$\mathbf{A}$

B

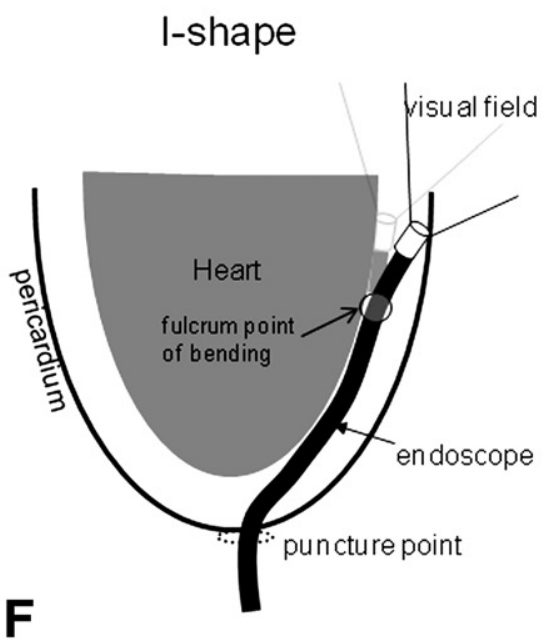

C

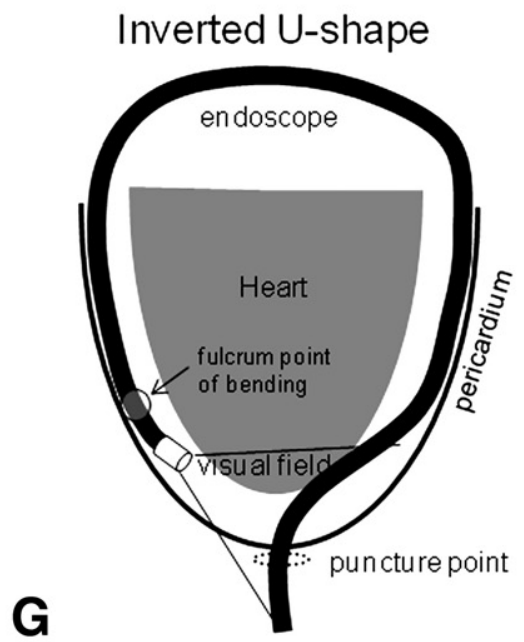

E

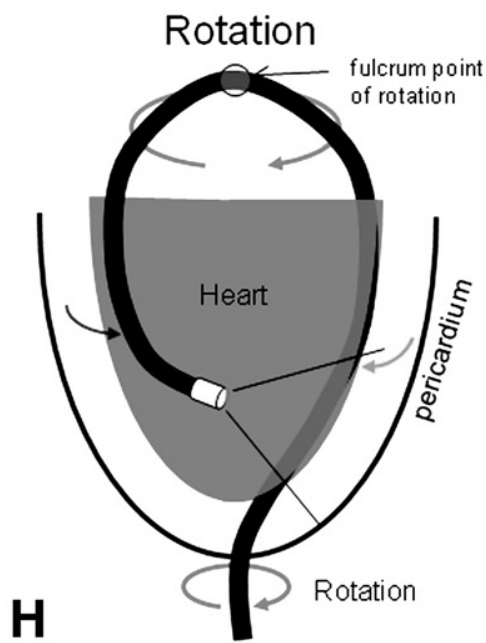

FIGURE 6. A-E, Sequential fluoroscopic images during changing I-shape configuration to inverted U-shape configuration. See details in text. F-H, Schematic diagram of I-shape configuration, inverted U-shape configuration of pericardial endoscope, and how to steer the tip of the endoscope in the pericardial space.

minor surgery (Figure 7, $F-H$ ). A needle-type pacing electrode (Figure 7,I) was transplanted into the left ventricular free wall by use of ES6 (Figure 7, $F-H$ ). Transplantation was successfully performed without significant hemodynamic change (Figure 7, $J-L$; Video 2 ).

\section{Complications}

Because pericardial endoscopy is the leading minimally invasive technique, the safety of this procedure is our main concern. In the process of puncture by the Seldinger technique, there were no complications, such as hemorrhages, pneumothorax, perforation of left ventricle, or other injuries. During the whole procedure, we could handle the devices in and out numerous times with no changes in blood pressure, pulse oxymetry data, or heart rate (Figure 3) for more than 1 hour. The injection of more than $200 \mathrm{~mL}$ of air into the pericardial space suppresses blood pressure by 5 to $10 \mathrm{~mm} \mathrm{Hg}$, but blood pressure recovers immediately by removing air from the space via endoscopic utility port.

In terms of chronic phases, pericardial inflammation was evaluated 2 weeks after the operations. There were no macroscopic injuries, coronary stenosis by coronary angiogram, hemorrhages, or adhesion of pericardium (Figure 7, D).

\section{DISCUSSION}

\section{Selection of Best Endoscope}

Because the first priority for pericardial endoscopy is a clear image, an endoscope with a CCD camera on the tip is essential. In popular endoscopes, the objective lens is usually positioned toward an anterior direction (forward-view, ES1, ES2, ES3, ES6). When the endoscope is inserted into the pericardial space, a shaft of the endoscope usually fits along the curve of the epicardial surface, but the objective lens faces toward a tangent direction to the epicardial surface and away from the surface of the heart (Figure 4, G). It is reasonable to imagine that positioning the objective lens in a 30- to 60-degree interior oblique direction may be another option (Figure $4, H$ ). From an optomechanical point of view, it is difficult to position the lens and CCD complex on the thin tip of endoscopes, although a lens with a 90-degree direction (lateral-view, ES4) can be achieved. Also, so-called fish-eye lenses or wider visual angle lenses (ES3, ES4, ES6) enable observation of the heart surface, even if the distance between the heart and the device is not sufficient.

A diameter less than $6.9 \mathrm{~mm}$ with a soft shaft is acceptable, and utility port is necessary for controlling air and devices. Among the ready-made endoscopes, the ES6 showed 


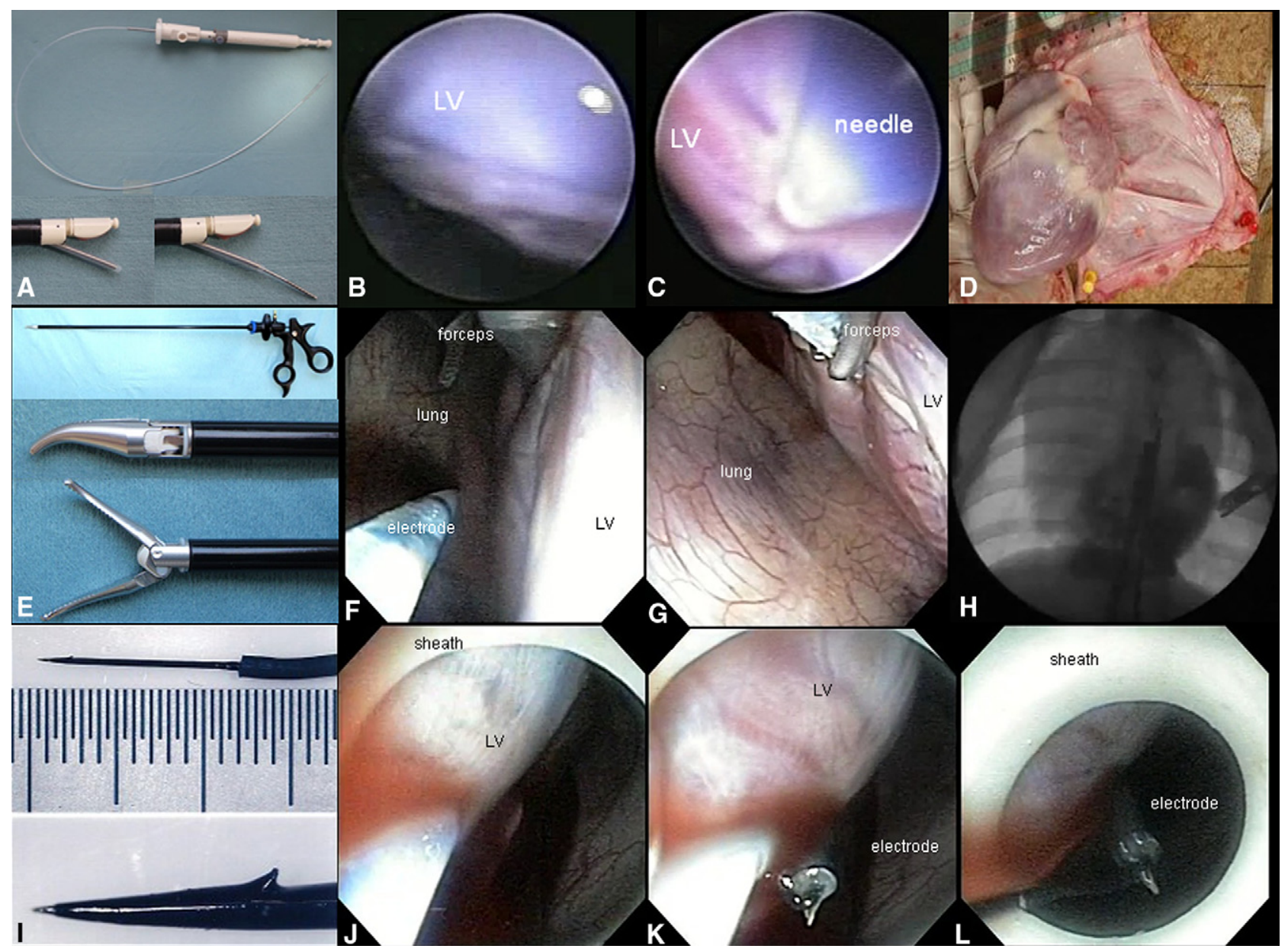

FIGURE 7. A-C, Indian ink was injected into the left ventricular epicardium with a needle. B, Immediately after injection of Indian ink, there was no active bleeding. D, Two weeks after the pericardial endoscopy, there was no coronary injury and no marked adhesion of pericardium. E, Laparoscopic forceps used. $F$, $G$, Endoscopic (ES6) images during implantation of pacing lead (I) in the left ventricular muscle by using laparoscopic forceps and fluoroscopic images during procedure $(\mathrm{H})$. Implanted pacemaker lead immediately after the implantation $(\mathrm{J}-\mathrm{L}) . L V$, Left ventricle.

the best performance. The ES4 also showed good performance, but there is no utility port for intervention.

\section{Selection of Best Sheath}

A certain length of the sheath should be positioned in the pericardial space to obtain back-up support for intervention. By advancing the sheaths, the direction of the sheath is usually perpendicular to the heart surface. A solid sheath causes significant compression of the heart surface and deterioration of hemodynamic parameters. Thus, a floppy sheath is suitable for pericardial endoscopy. Furthermore, to maintain the amount of air within the pericardial space, a check valve at the top of the sheath is essential. Taking this into account, we selected SH4 as the best sheath for pericardial endoscopy.

\section{Stabilization of Motion Artifacts}

Stabilization of strong motion artifacts is important. Keeping a distance from the heart surface by use of the in- verted U-shape configuration can help stabilize the visual field. Gentle compression of the heart by a rigid manipulator, such as sheaths and laparoscopic forceps, can also stabilize the heartbeat.

\section{Optimization of the Tools}

Although we demonstrated the feasibility of the pericardial endoscope by ready-made endoscopes, optimization of the tools should be required. The ES6 is almost acceptable as a pericardial endoscope if we have welldesigned forceps for interventions through the utility port. On the other hand, further optimization of the manipulator should be done for pericardial interventions, such as an optimized tool for a cell-delivery system, epicardial pacemaker implantation, and curving of the tip to fit along the heart curvature. The design for the sheath should also be optimized. The optimal material, stiffness, and curve of the sheath remain to be elucidated. 


\section{Limitations}

Before application for human use, the pericardial endoscopic system should be optimized, and further experiments should be done in other conditions. For example, we did not try the system on an animal with heart failure; therefore, the feasibility of the procedure in the patient with severe heart failure is still undetermined.

We performed the experiment under general anesthesia with respirator support, but for humans this procedure could be performed with local anesthesia. However, in patients with congenital pericardial defect, of which there is a prevalence of $0.0001 \%{ }^{19}$ to $0.044 \%,{ }^{20}$ infusion of the gas may cause pneumothorax, so respirator support should be required in such cases.

During this procedure, coincidental occurrence of ventricular fibrillation should be carefully monitored. If this occurs, immediate suction of the gas should be required to perform successful external defibrillation.

It was difficult to observe the posterior surface of the heart because of the limited space between the posterior wall of left atrium and the spine. If the target is the posterior portion of the heart, a lateral position of the patient may gain space and avoid puddling at the focus area. Further experiments should be done for safer procedures.

\section{Clinical Applications}

The future of this new technique relies on optimizing its use in humans. Previous studies have demonstrated the effective use of the pericardial approach in the human body, and the device itself is already well known and used clinically. Therefore, there are no obstacles to human application. This method enables us to reach epicardial areas and deep into the myocardium to focus on ablation and implantable cardioverter/defibrillator lead placement in a minimally invasive way. In the present study, we infused air into the pericardial space. However, there is less chance of causing air embolism and significant mediastinal emphysema with carbon dioxide compared with air. For clinical application, infusion of carbon dioxide gas is considered to be safer in this system.

Moreover, in cardiac stem cell therapy, there is no standard method of stem cell transplantation. Transplantation via coronary vessels may not deliver the cells to the appropriate location in the heart tissue, may occlude coronary vessels, and may generate additional myocardial infarctions. ${ }^{7}$ Direct injection into the myocardium from an endocardial site via a needle devised on the tip of a catheter using an electroanatomic mapping system (NOGA System, Biosense Webster, Markham, ON, Canada) ${ }^{6}$ is similar to the common catheter ablation procedure. Although the catheter procedure is safe and can be performed repeatedly, the injected cells may backflush into the left ventricular cavity via needle trajectory and disseminate into the systemic circulation, causing systemic microembolizations. From this point of view, injection of the cells from the epicardial surface is secure. However, open chest surgery is required to avoid coronary vessels. Pericardial endoscopy-guided cellular transplantation from the epicardial surface can be a major method for stem cell transplantation.

\section{CONCLUSIONS}

Our experiment has established a new and simple method for obtaining a clear view of the pericardial space with the use of pericardial endoscopy. The percutaneous subxyphoid approach using the Seldinger technique was useful and safe. An x-ray fluoroscopic guide was necessary to steer the endoscope in the pericardial space. We have shown short- and long-term safety with regard to hemodynamic changes, infections, and adhesion of pericardium. Pericardial endoscopy can introduce a new era of technology for cardiac surgeons and cardiac interventionists.

The authors thank Olympus Corporation for technical advice and Satoshi Ogawa, MD, PhD, and Toshiaki Satoh, MD, PhD, for medical advice.

\section{References}

1. Gruntzig AR, Senning A, Siegenthaler WE. Nonoperative dilatation of coronaryartery stenosis: percutaneous transluminal coronary angioplasty. N Engl J Med. 1979;301:61-8

2. Gallagher JJ, Svenson RH, Kasell JH, German LD, Bardy GH, Broughton A, et al. Catheter technique for closed-chest ablation of the atrioventricular conduction system. N Engl J Med. 1982;306:194-200.

3. Scheinman MM, Morady F, Hess DS, Gonzalez R. Catheter-induced ablation of the atrioventricular junction to control refractory supraventricular arrhythmias. JAMA. 1982;248:851-5.

4. Abraham WT, Fisher WG, Smith AL, Delurgio DB, Leon AR, Loh E, et al. Cardiac resynchronization in chronic heart failure. $N$ Engl J Med. 2002;346: 1845-53.

5. Cribier A, Eltchaninoff H, Bash A, Borenstein N, Tron C, Bauer F, et al Percutaneous transcatheter implantation of an aortic valve prosthesis for calcific aortic stenosis: first human case description. Circulation. 2002; 106:3006-8

6. Perin EC, Dohmann HF, Borojevic R, Silva SA, Sousa AL, Mesquita CT, et al. Transendocardial, autologous bone marrow cell transplantation for severe, chronic ischemic heart failure. Circulation. 2003; 107:2294-302.

7. Vulliet PR, Greeley M, Halloran SM, MacDonald KA, Kittleson MD. Intra-coronary arterial injection of mesenchymal stromal cells and microinfarction in dogs. Lancet. 2004;363:783-4.

8. Breitbach M, Bostani T, Roell W, Xia Y, Dewald O, Nygren JM, et al. Potential risks of bone marrow cell transplantation into infarcted hearts. Blood. 2007;110: 1362-9.

9. Kikuchi K, McDonald AD, Sasano T, Donahue JK. Targeted modification of atrial electrophysiology by homogeneous transmural atrial gene transfer. Circulation. 2005;111:264-70.

10. Ota T, Degani A, Zubiate B, Wolf A, Choset H, Schwartzman D, et al. Epicardial atrial ablation using a novel articulated robotic medical probe via a percutaneous subxiphoid approach. Innovations Phila Pa. 2006;1:335-40.

11. Soejima K, Couper G, Cooper JM, Sapp JL, Epstein LM, Stevenson WG. Subxiphoid surgical approach for epicardial catheter-based mapping and ablation in patients with prior cardiac surgery or difficult pericardial access. Circulation 2004;110:1197-201. 
12. Soejima K, Stevenson WG, Sapp JL, Selwyn AP, Couper G, Epstein LM. Endocardial and epicardial radiofrequency ablation of ventricular tachycardia associated with dilated cardiomyopathy: the importance of low-voltage scars. J Am Coll Cardiol. 2004;43:1834-42.

13. Maisch B, Bethge C, Drude L, Hufnagel G, Herzum M, Schonian U. Pericardioscopy and epicardial biopsy-new diagnostic tools in pericardial and perimyocardial disease. Eur Heart J. 1994;15(Suppl C):68-73.

14. Seferovic PM, Ristic AD, Maksimovic R, Tatic V, Ostojic M, Kanjuh V. Diagnostic value of pericardial biopsy: improvement with extensive sampling enabled by pericardioscopy. Circulation. 2003;107:978-83.

15. Nazarian S, Kantsevoy SV, Zviman MM, Matsen FA 3rd, Calkins H, Berger RD, et al. Feasibility of endoscopic guidance for nonsurgical transthoracic atrial and ventricular epicardial ablation. Heart Rhythm. 2008;5:1115-9.
16. Gerosa G, Bianco R, Buja G, di Marco F. Totally endoscopic robotic-guided pulmonary veins ablation: an alternative method for the treatment of atrial fibrillation. Eur J Cardiothorac Surg. 2004;26:450-2.

17. Zenati MA, Bonanomi G, Chin AK, Schwartzman D. Left heart pacing lead implantation using subxiphoid videopericardioscopy. J Cardiovasc Electrophysiol. 2003; 14:949-53.

18. Spodick DH. The technique of pericardiocentesis. When to perform it and how to minimize complications. J Crit Illn. 1995;10:807-12.

19. Southworth H, Stevenson CS. Congenital defects of the pericardium. Arch Intern Med. 1938;223-40.

20. Van Son JA, Danielson GK, Schaff HV, Mullany CJ, Julsrud PR, Breen JF. Congenital partial and complete absence of the pericardium. Mayo Clin Proc. 1993; 68:743-7. 